Lisi Hu, Irrum Afzal*, Roy Twyman, Deiary Kader

\title{
Can Body Height Be Used to Predict Knee Implant Sizes?
}

South West London Elective Orthopaedic Centre, London, United Kingdom

* Corresponding author: Irrum Afzal, South West London Elective Orthopaedic Centre, London, United Kingdom

Received date: February 06, 2020; Accepted date: February 19, 2020; published date: February 24, 2020

Citation: Lisi Hu, Irrum Afzal, Roy Twyman, Deiary Kader (2020) Can Body Height Be Used to Predict Knee Implant Sizes? J Clinical Research and Reports, 3(1); DOI:10.31579/2690-1919/040

Copyright: (C) 2020 Irrum Afzal. This is an open access article distributed under the Creative Commons Attribution License, which permits unrestricted use, distribution, and reproduction in any medium, provided the original work is properly cited.

\section{Abstract:}

Introduction:Accuracy of pre-operative templating using radiographs or joint replacement programmes is variable. Implant modularity has increased the number of sizes available and trays used per procedure. Multiple intra-operative implant size trials lead to longer surgery time and greater instrument maintenance costs.

It was hypothesised that patient factors could predict the size of implant and tray required, thereby increasing efficiency and reducing operative time.

This study aims to identify correlation between implant size and body height to improve efficiency and reduce costs.

Method: This prospective cohort study includes patients who underwent primary total knee replacement using the DePuy ATTUNE® Primary Total Knee System between $1^{\text {st }}$ January 2016 to $7^{\text {th }}$ August 2017 performed by a single surgeon, at a single hospital. Post-operative x-rays were reviewed for appropriate implant sizing.

The DePuy ATTUNE® Primary Total Knee System has five sets, split into sizes 1-2, 3-5, 6-8 and 9-10.

Results: 188 patients (205 knees) were included, 66 male and 122 female. Male height was $174.6 \mathrm{~cm}(152-194.3)$ with average implant size 8 . Female height was $158.7 \mathrm{~cm}$ (145-177.8) with average implant size 5. The Spearman rank correlation between body height, femoral and tibial size were 0.793 and 0.837 respectively. All men $<170 \mathrm{~cm}$ and $>185 \mathrm{~cm}$ used the $6-8$ and $9-10$ set respectively. All women $<150 \mathrm{~cm}$ and $>170 \mathrm{~cm}$ used the $3-5$ and $6-8$ set respectively.

Conclusion:The positive correlation identified coincides with existing literature. Using extremes of height and gender, surgeons and theatre staff could predict the likely trial set required, improve theatre efficiency and reduce costs.

Key Words: arthroplasty; replacement; knee; body height

\section{Introduction:}

Pre-operatively planning in orthopaedic surgery can help anticipate problems that may arise intraoperatively and plan for appropriate equipment, therefore improving surgical efficiency and patient care(1). As part of planning for Total Knee Replacements (TKR), predicting the correct femoral and tibial component is an important step for surgeons. Accurate component size selection can aid proper knee biomechanics, therefore decreasing pain and the need for revision surgery, as well as the appropriate management of theatre stock, reducing intra-operative size trials, operating time and its associated complications(2). In 2014-2015, 2.3 million surgical instruments were sterilised in a single NHS trust, costing $£ 2,484,000$ per annum(3). Accurate component size prediction can reduce the number of size trials and surgical equipment trays being opened, therefore reducing sterilisation costs.

Traditional templating methods, using pre-operative plain radiographs and acetate, or digital templating using joint replacement computer programmes have variable accuracy(2). More recently, the use of three-dimensional templating or patientspecific instrumentation has shown very high accuracy for the prediction of actual implant size used, but is more costly in time and money(4). However, these templating methods should only be used as a guide for initial size trialling intra-operatively.

Implant modularity have increased the number of femoral and tibial component sizes and the number of trays used per procedure. Sizing is important in ligamentous balancing, allowing stability throughout full range of motion. Flexion space too small can lead to reduced range of motion or wear of the polyethylene insert, while a space too large may result in mid-flexion instability(5).

The DePuy ATTUNE® Primary Total Knee System has 10 femoral and tibial component sizes available, with an additional four narrow femoral component sizes, to meet the needs of the diverse worldwide population. There are five trays for the trial sizes. The femoral component trays are split into sizes 3-5 and 68 , while the tibial components are grouped in one tray with sizes 3-8. There are two combination trays of both femoral and tibial components, in sizes 1-2 and 9-10(6).

It has been thought that patient variables such as gender and body height can correlate to the implant size, and can be used as a part of pre-operatively planning.

The aim of this study was to identify if there was correlation between body height and the size of the ATTUNE® Primary Total Knee System, which may aid pre-operative planning and surgical efficiency.

\section{Material and methods:}

This was a retrospective analysis of prospectively collected comprehensive data set. This study was undertaken at a single hospital, using single surgeon data. All patients who underwent a primary TKR using the ATTUNE® Primary Total Knee System under the care of this single surgeon from 1st January 2016 to 7 th of August 2017 were identified and included in this study. Postoperative $\mathrm{x}$-rays were reviewed for appropriate sizing of implants. 
A total of 188 patients were included, 17 underwent bilateral knee replacements, resulting in a total of 205 knee replacements. The average age was 73.3 (53-89). There were no other exclusion criteria.

The implant sizes were recorded on the local hospital operating theatre software, Bluespier.

All the implant sizes recorded on Bluespier were validated against the femoral and tibial implant stickers recorded in the implant books. No discrepancies were identified.

The body height for all 205 knee replacements were obtained from the Pre-Operative Assessment, recorded on Bluespier, and recorded in centimetres $(\mathrm{cms})$ to allow for consistency in the study.
$\mathrm{R}^{2}$ coefficients were calculated using the Spearman Rank Correlation between each of the femoral and tibial components to determine if there was a correlation between body height and implant size.

This study was an audit approved by the local trust Research and Development team and did not require ethical approval.

\section{Results:}

188 patients (205 knees) were identified from the inclusion and exclusion criteria, 66 male and 122 female. Body height were recorded for each knee replacement, allowing for slight changes in body height for the same patient over time. The average male height was 174.6 (152-194.3) and average female height was 158.7 (145-177.8).

\begin{tabular}{|c|l|l|l|l|l|l|}
\hline Gender & $\begin{array}{l}\text { Femoral size } \\
\text { range }\end{array}$ & $\begin{array}{l}\text { Femoral } \\
\text { size median }\end{array}$ & $\begin{array}{l}\text { Femoral } \\
\text { size mode }\end{array}$ & $\begin{array}{l}\text { Tibial size } \\
\text { range }\end{array}$ & $\begin{array}{l}\text { Tibial } \\
\text { size } \\
\text { median }\end{array}$ & $\begin{array}{l}\text { Tibial size } \\
\text { mode }\end{array}$ \\
\hline Male & $5-10$ & 8 & 7 & $6-10$ & 8 & 7 \\
\hline
\end{tabular}

\begin{tabular}{|l|l|l|l|l|l|l|}
\hline & & & & & & \\
\hline Female & $3-8$ & 5 & 5 & $3-7$ & 5 & 5 \\
\hline
\end{tabular}

\section{Table 1. Femoral and tibial implant sizes split by gender}

\section{Body Height vs Femoral Component Size}

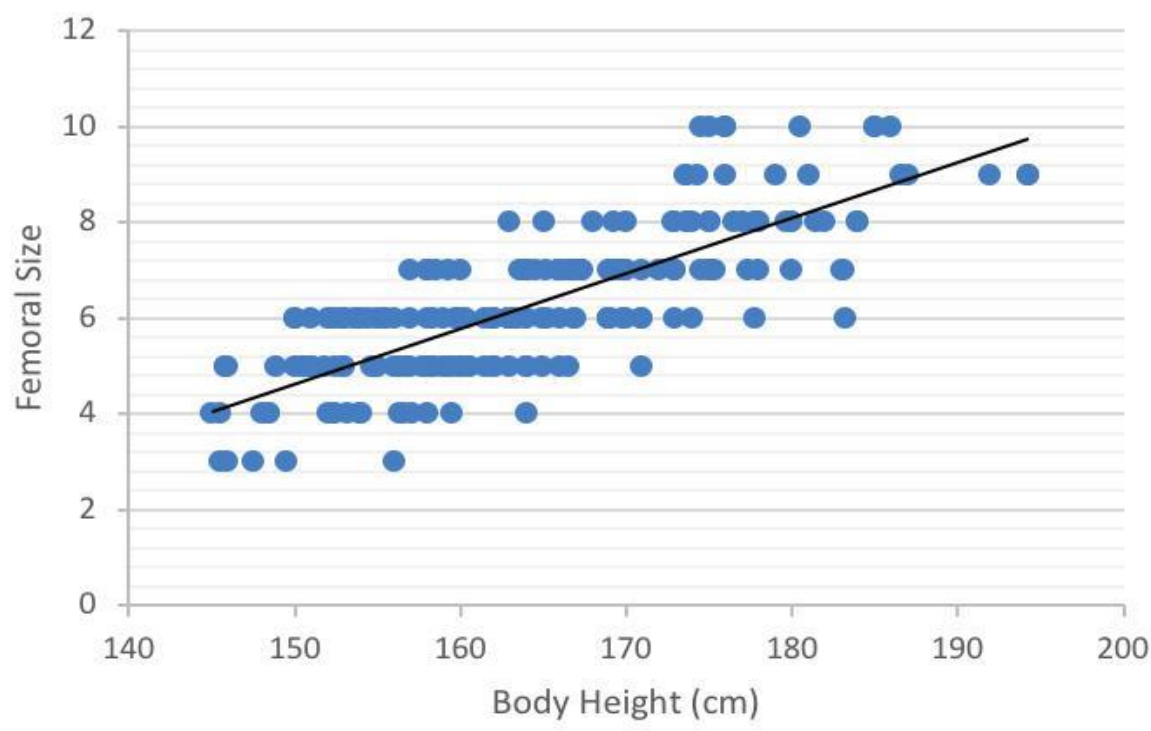

Figure 2. Correlation between body height and femoral component size 


\section{Body Height vs Tibial Component Size}

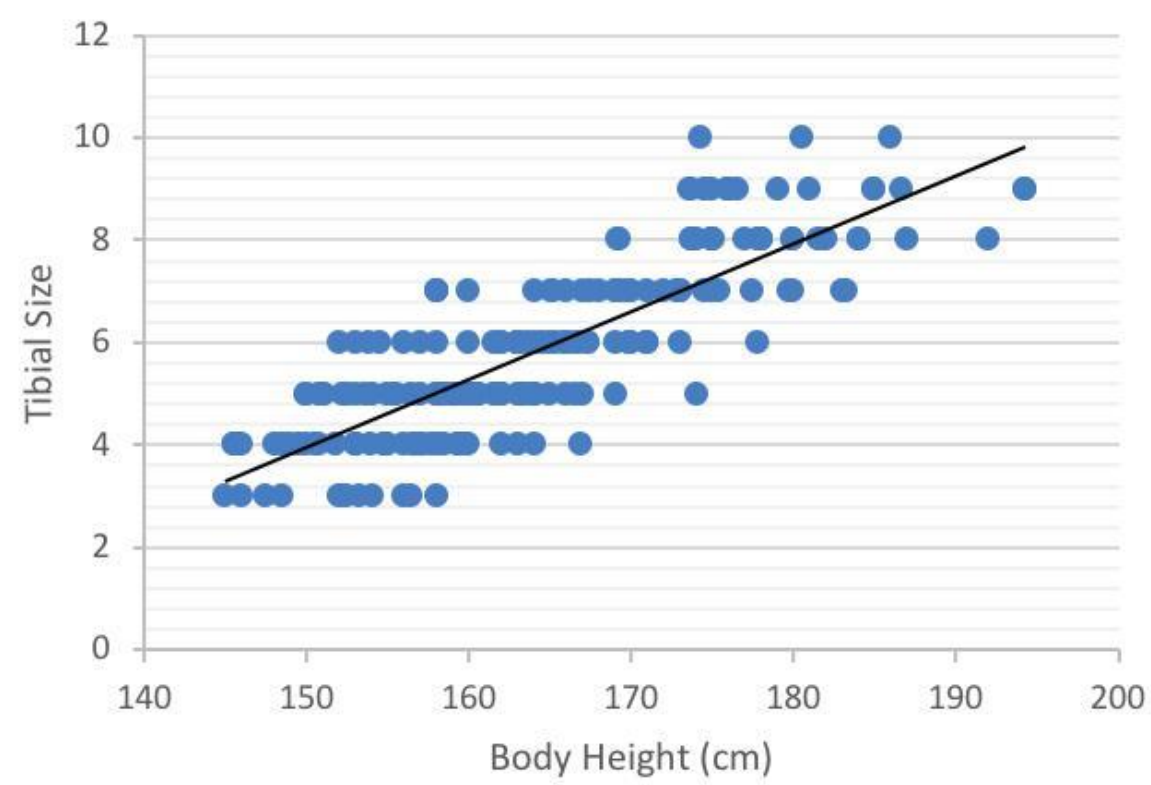

Figure 3. Correlation between body height and tibial component size

\begin{tabular}{|c|c|c|c|}
\hline Components & Mixed Height & Female height & Male height \\
\hline Femoral & 0.793 & 0.581 & 0.612 \\
\hline Tibial & 0.837 & 0.647 & 0.633 \\
\hline
\end{tabular}

Table 4. $\mathrm{R}^{2}$ coefficients for tibial and femoral components when compared to gender based height

\begin{tabular}{|c|c|c|c|c|c|c|}
\hline \multirow{2}{*}{$\begin{array}{l}\text { Implant } \\
\text { size }\end{array}$} & \multicolumn{6}{|c|}{ Height (cm) } \\
\hline & $<150$ & $150-154.9$ & $155-159.9$ & 160-164.9 & $165-169.9$ & $170+$ \\
\hline $3-5$ & 100 & 62 & 65 & 37 & 16 & 0 \\
\hline $6-8$ & 0 & 38 & 35 & 63 & 84 & 100 \\
\hline
\end{tabular}

Table 5. Percentage of femoral implants used, split by sizes, in females 


\begin{tabular}{|l|c|c|c|c|c|c|}
\hline \multirow{2}{*}{$\begin{array}{l}\text { Implant } \\
\text { size }\end{array}$} & $<170$ & $170-174.9$ & $175-179.9$ & $180-184.9$ & $185-189.9$ & $190+$ \\
\cline { 2 - 7 } & 100 & 73 & 71 & 83 & 0 & 0 \\
\hline $9-8$ & 0 & 21 & 29 & 17 & 100 & 100 \\
\hline
\end{tabular}

Table 6. Percentage of femoral implants used, split by sizes in males

\begin{tabular}{|c|c|c|c|}
\hline Female height $(\mathrm{cm})$ & $\begin{array}{l}\text { Average } \\
\text { Femoral }\end{array}$ & \multicolumn{2}{|c|}{ Estimated femoral tray } \\
\hline$<150$ & 4 & 5-Mar & 165 \\
\hline $150-159$ & 5 & $3-5$ or $6-8$ & 166 \\
\hline $160-169$ & 6 & $3-5$ or $6-8$ & 167 \\
\hline $170-179$ & 7 & 8-Jun & 168 \\
\hline \multicolumn{4}{|c|}{ Male height group (cm) } \\
\hline$<160$ & 6 & 8-Jun & 169 \\
\hline $160-169$ & 7 & 8-Jun & 170 \\
\hline $170-179$ & 8 & $6-8$ or $9-10$ & \\
\hline 180-189 & 8 & $6-8$ or $9-10$ & \\
\hline $190+$ & 9 & 10-Sep & 172 \\
\hline
\end{tabular}

Table 7. Estimated femoral tray required when separated by gender and height.

Our study illustrated a positive correlation between body height and the ATTUNE® Primary Knee implant sizes. The strongest correlation was seen between body height and the tibial component.

When separated by gender, a positive correlation was also demonstrated in all groups. Men required larger components than women in the same height group, where on average men were one size bigger. Of the 205 knee replacements, no patients required the use of size 1-2 kit, and only men required components from the size 9-10 kit.

\section{Discussion}

Our data was limited to a single surgeon at a single hospital, producing a small cohort of patients. The patient population referred to this single hospital may demonstrate an uneven distribution of ethnicitiy and Body Mass Index compared to the general population, therefore our data may not be transferable to other centres. However, we took steps to ensure the accuracy of the data captured, including using two sources to identify the size of implants used.

This study identified one outlier, who was a male patient with a height of $171 \mathrm{~cm}$ and required a size five femoral implant, the only male patient who required the size 3-5 femoral tray to be opened. Therefore it is worth noting that the correlation between height and implant size is a guide, and surgeons and theatre staff should be prepared to open kits which may not have been anticipated based on patient height and gender. 
Hernandez-Vaquero et al., conducted a double-blind study evaluating the accuracy of templating 50 primary TKRs using the same surgeon and implant (Triathlon ${ }^{\circledR}$ Knee System (Stryker, Mahwah, New Jersey, United States)) with eight femoral and tibial sizes each. They found that using traditional radiographic methods alone, correct templating of the femoral and tibial components to the implanted occurred in 55\% and 50\% respectively, and sizing to within one size were $90 \%$ and $94 \%$ respectively (7).

Fawzy et al., correlated body height with the Oxford unicompartmental knee implant (four sizes available), concluding that height based on gender is a reliable method for predicting the femoral component size in 100 patients(8).

Trainer et al., compared shoe size and height with the DePuy PFC Sigma or DePuy Attune implant size in 100 primary TKRs by a single surgeon, and found shoe size to be a better predictor in determining implant size compared to height, particularly the tibial component (9).

Shershon et al., reviewed 3377 primary TKRs using implants from six different manufacturers, and found a linear correlation between height, weight and gender for implant sizes and performed a regression analysis, showing that using radiographic templating alongside demographic data allowed prediction within one size to $90 \%-99 \%$ for femoral and tibial components, and is superior to using demographic data alone (1).

While our findings confirm the existing literature regarding the correlation between implant size and patient demographics, we also looked at the data with a view to improve theatre efficiency and reduce costs.

\section{Conclusion:}

We can use gender and the extremes of height range to help surgeons and theatre staff predict which size trial set is likely to be used, and therefore limit the number of unnecessary trays being opened, subsequently reducing theatre time, equipment maintenance and sterilization costs and improving theatre efficiency.

The relationship between implant size and body height can be used to facilitate equipment management and streamline intraoperative efficiency by using it to predict the operative kit and size of implant likely to be used, and therefore ensure it is in stock and on standby. Body height can be used alongside radiographic templating to ensure the most accurate method to determine implant size is used pre-operatively for best patient outcomes and surgical efficiency.

\section{Acknowledgements:}

With thanks to Mohamed Tarek and Mohamed Alrashdan for their assistance in data collection.

\section{Patient Consent:}

Patient consent was not required for the purposes of this study.

\section{Disclosure:}

The authors report no conflict of interest concerning the materials or methods used in this study or the findings specified in this paper." The corresponding author is responsible for the accuracy and completeness of the submitted information.

\section{References}

1. Sershon RA, Courtney PM, Rosenthal BD, Sporer SM, Levine BR. Can Demographic Variables Accurately Predict Component Sizing in Primary Total Knee Arthroplasty? J Arthroplasty [Internet]. 2017;32(10):3004-8.

2. Miller AG, Purtill JJ. Total Knee Arthroplasty Component Templating. J Arthroplasty. 2012;27(9):1707-9.

3. O'Brien T. Re: Freedom of Information request - Ref: FOI 3201 [Internet]. Epsom and St Helier. 2016 [cited 2018 Aug 29].

4. Ettinger M, Claassen L, Paes P, Calliess T. 2D versus 3D templating in total knee arthroplasty. Knee [Internet]. 2016 Jan 1 [cited 2018 Aug 8];23(1):149-51.

5. Incavo SJ, Coughlin KM, Beynnon BD. Femoral Component Sizing in Total Knee Arthroplasty Size Matched Resection Versus Flexion Space Balancing. 2004.

6. DePuy Synthes. ATTUNE ® KNEE SYSTEM ORDERING INFORMATION [Internet]. 2015 [cited 2018 Aug 9].

7. Hernandez-Vaquero D, Abat F, Sarasquete J, Monllau JC. Reliability of preoperative measurement with standardized templating in Total Knee Arthroplasty. World J Orthop.

8. Fawzy E, Pandit H, Jenkins C, Dodd CAF, Murray DW. Determination of femoral component size in unicompartmental knee replacement. Knee [Internet]. 2008 Oct [cited 2018 Aug 8];15(5):403-6.

9. Trainor S, Collins J, Mulvey H, Fitz W. Total Knee Replacement Sizing: Shoe Size Is a Better Predictor for Implant Size than Body Height. Arch bone Jt Surg [Internet]. 2018Mar [cited 2018 Aug 8];6(2):100-4. 